\title{
Produtividade que mata
}

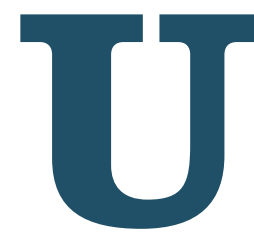

m economista distante no tempo que tentasse entender o colapso da indústria americana no ano de 2008 ficaria perplexo ao constatar que, nesse mesmo ano, a produtividade das empresas dos EUA seguia de vento em popa. Como então explicar as ondas de enxugamento de pessoal, de fusões fracassadas, de agressão ao meio ambiente e a derrocada dos sindicatos? Este artigo, escrito ficticiamente no futuro, demonstra como a produtividade observada nesse período era, na verdade, de tipo altamente nocivo.

\section{por Henry Mintzberg McGill University}

Analisando em retrospecto a grande depressão que começou em 2008, os economistas oferecem suas explicações corriqueiras. O desequilíbrio comercial americano era enorme havia anos; o governo Bush estava acumulando enormes déficits orçamentários; os americanos não poupavam - muitos hipotecavam repetidas vezes suas casas para manter seus gastos; confiava-se que investidores estrangeiros, principalmente o governo da China, forneceriam os recursos faltantes. Isso não podia durar, concordam os economistas em retrospecto; a gota d'água caiu em 2008.

Mas há uma coisa que ainda intriga esses economistas. A economia americana parecia ir tão bem naquela época! As 
empresas apresentavam lucros robustos e pareciam incrivelmente eficientes. "Aumenta a produtividade nos EUA", dizia uma manchete do International Herald Tribune, em dezembro de 2005, com o subtítulo "Diminuem os custos do trabalho à medida que a produção aumenta". Parecia muito alentador. Como isso pôde acontecer?
Naquela estranha época, o "valor para o acionista" nada tinha a ver com o valor da empresa, quanto mais com qualquer valor humano. Era um eufemismo para a prática de aumentar o preço das ações o mais rapidamente possível. Isso se tornara uma febre na década de 2000, com os analistas de mercado exercendo enorme pressão sobre os altos executivos para que Naquela estranha época, 0 "valor para 0 acionista" nada tinha a ver com o valor da empresa, quanto mais com qualquer valor humano. Era um eufemismo para

\section{a prática de aumentar o preço das ações}

\section{o mais rapidamente possível.}

Ganhos como perdas. A resposta está nas estatísticas usadas pelos macroeconomistas; e por trás das teorias dos microeconomistas, que sempre enxergaram a empresa como um indivíduo: o empreendedor-fundador ou um executivochefe que maximizasse o "valor para o acionista". Sob seus líderes, para além de sua produtividade, grande parte do setor empresarial americano apodrecia de dentro para fora. A produtividade estava destruindo as grandes empresas americanas e o lendário espírito empreendedor do país.

Muitos dos ganhos de produtividade eram, na verdade, perdas de produtividade. Para entender isso, imagine-se como líder de uma grande empresa americana, nos idos de 2008, que desejasse ganhar dinheiro para a empresa - e para si mesmo - o mais rápido possível, contribuindo, ao mesmo tempo, para as estatísticas de produtividade. Qual seria a melhor estratégia?

Demitir todo o mundo e vender a partir do estoque. As horas trabalhadas diminuem enquanto as vendas continuam - ou até aumentam, já que há todo tipo de incentivo para reduzir os preços e acabar com o estoque. Assim, a produtividade decola enquanto você ganha um dinheirão até, é claro, que o estoque acabe. Isso era, quase literalmente, o que acontecia no setor empresarial americano. Em 2008 acabou o estoque. continuassem a inflar o valor de mercado de suas ações.

Embora possa ser difícil acreditar, naquela época as companhias abertas tinham de publicar seus resultados a cada trimestre, como se fosse possível discernir alguma alteração do destino de uma grande empresa entre os meses de outubro e dezembro. A idéia era, de fato, ridícula. Mas cumpria sua função: manter a alta administração firmemente focada no desempenho mensurável, em vez de focada nos produtos, serviços e clientes; ou seja, nos resultados de hoje, não na sustentabilidade de amanhã.

Liderança como saga heróica. Mas como podiam os empregados dessas empresas concentrar toda a sua atenção na maximização do valor para o acionista, quando a maioria desses empregados jamais se encontrara com eles, a maioria dos quais day traders que compravam as ações pela manhã para vendê-las à tardinha? Que incentivo havia para que os empregados servissem essas pessoas, especialmente quando o valor para o acionista descartava expressamente qualquer direito que eles mesmos pudessem ter sobre os resultados de seu trabalho?

De forma coerente com a visão econômica da empresa de que falamos anteriormente, a resposta era (a) responsabilizar uma pessoa - o CEO - pelo desempenho de toda a empresa; (b) motivar essa pessoa por meio de opções de ações e estratégias similares; e (c) dar-lhe carta branca para agir a seu critério - e rapidamente. Naturalmente, não havia trégua na retórica sobre a construção da cultura da empresa a longo prazo, sobre o incentivo do trabalho de equipe entre trabalhadores do conhecimento, etc. Mas a realidade era o inverso: as empresas centralizavam o poder em seus CEOs de uma forma que não se via havia décadas. 
Que importava se isso era uma enorme injustiça com a capacidade da empresa de operar enquanto entidade cooperativa? E daí que um CEO novo, com parco conhecimento da empresa, de sua cultura e de seus clientes, podia chegar em seu cavalo branco e acabar com tudo o que a empresa construíra ao longo de anos? Era preciso servir aos mercados financeiros, e isso significava inaugurar a era da liderança heróica, para que uma só pessoa pudesse levar implacavelmente todas as outras a elevar o desempenho mensurável de curto prazo, não importava como.

Corrupção legal. Mas como? Como esses líderes heróicos conseguiram elevar tão rapidamente os preços das ações? Alguns, como sabemos, simplesmente trapacearam, fazendo manobras contábeis para que tudo parecesse ir bem. Mas essa corrupção ilegal, que, uma vez descoberta, podia ser submetida aos tribunais, era apenas a ponta do iceberg. Muito mais abrangente e insidiosa era a corrupção dentro da lei, que equivalia a transformar em dinheiro o "nome na praça" que muitas empresas haviam nutrido com tanto carinho ao longo de tantos anos.
Como isso era algo que os contabilistas tinham dificuldade em quantificar, não importava. Por outro lado, para eles era fácil medir os lucros a curto prazo, assim como o era para os economistas medir a produtividade. Os CEOs gerenciavam com muito cuidado esse desempenho, freqüentemente dedicando-lhe mais atenção que ao negócio em si. O objetivo era enganar os analistas financeiros, ou, pelo menos, as pessoas que os analistas financeiros haviam convencido a comprar as ações. Com isso, empregados das mais diferentes áreas tinham sua atenção desviada para traçar planos que impressionassem investidores externos. Uma pessoa com quem conversei riu ao falar dos grandes debates que se formavam em torno de apresentações em Powerpoint sobre planos que, todos na empresa sabiam, jamais seriam colocados em prática.

Outras estratégias populares eram depreciar a marca (pequenos Mercedes, à medida que diminuía a qualidade da Daimler) e explorar a clientela (extrair tudo o que a empresa pudesse no plano imediato, deixando de lado a fidelização), sempre, é claro, em nome da "qualidade" do produto e do "serviço" ao cliente.

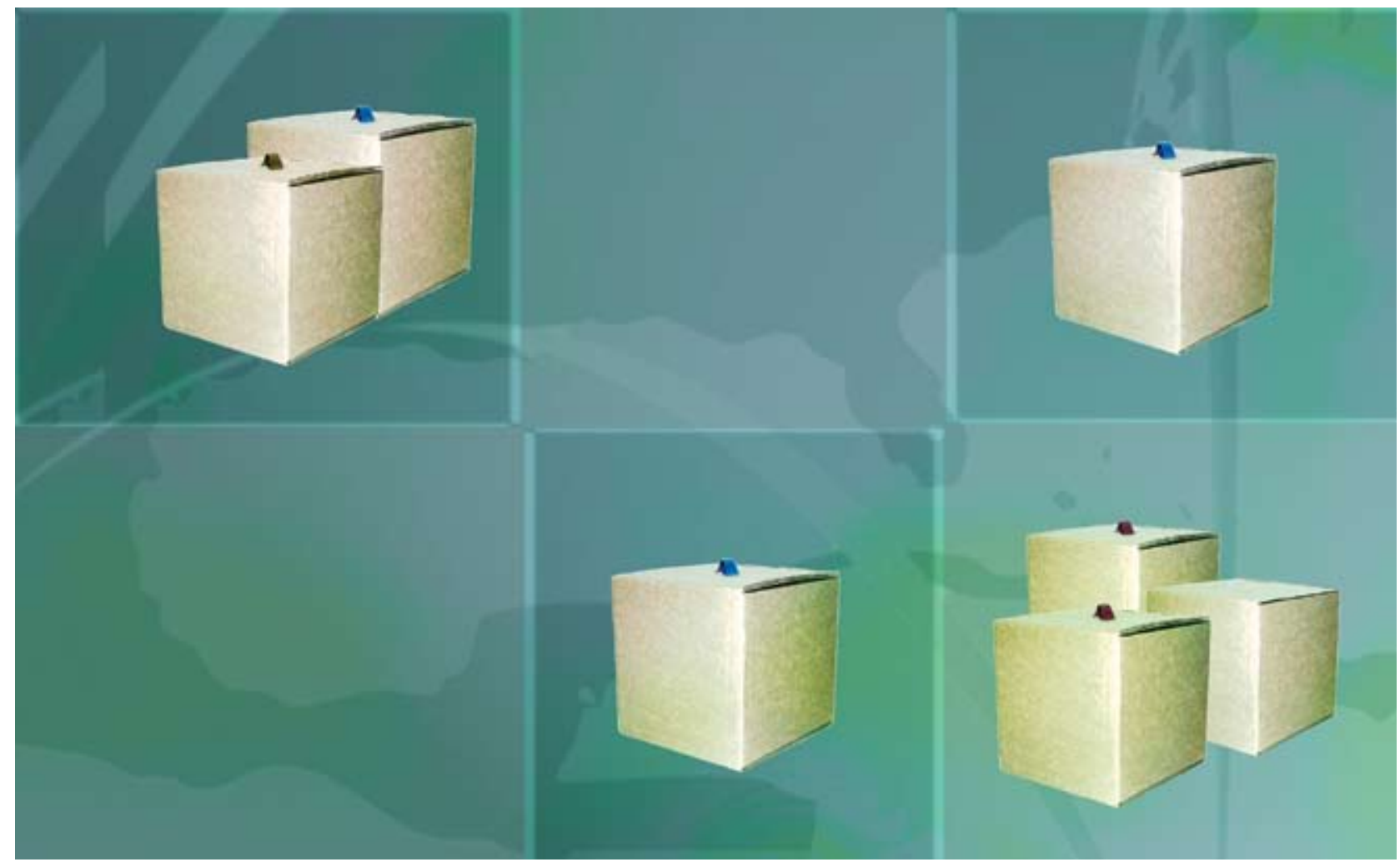


As "fusões" (na verdade, aquisições) também eram populares: fechar o negócio e jogar para os outros as conseqüências de fazer com que ele funcionasse. O truque era ser maior, não melhor, do que os concorrentes. Ser melhor exigia tempo e esforço.Com a eliminação de alguns dos concorrentes, não era mais tão difícil se tornar o melhor. Claro que algumas dessas fusões fracassaram, muitas vezes de forma vergonhosa. Mas, a essa altura, a maioria dos CEOs já havia ido embora, tendo gozado do holofote da atenção pública no meio tempo.

Ainda mais popular - e o que mais se aproximava de vender o estoque - era o "downsizing", um eufemismo para demitir a torto e a direito operários e gerentes de médio escalão. Ao menor sinal de queda do preço da ação, ainda que a empresa continuasse lucrativa, lá se iam pessoas de todos os tipos porta afora, migalhas jogadas para distrair os cães famintos do establishment financeiro.

\section{Recursos humanos em vez de seres humanos.}

Infelizmente, contudo, essas migalhas - ou, para usar o vocabulário real e não menos aviltante da época, esses "recursos humanos" - eram pessoas de carne e osso. Recursos são coisas; não se importam de serem descartados. Seres humanos são pessoas e se importam, sim. E mais: ao saírem da empresa, esses seres humanos levavam na cabeça os bancos de dados de suas organizações. Claro que sempre haveria informações úteis nos computadores - informações explícitas. Porém, muito mais importantes eram as informações tácitas que residiam na mente de pessoas experientes, e nenhuma corporação contava com um programa que pudesse fazer download disso.

Essas pessoas também traziam consigo o coração e a alma de suas empresas, pois não era a liderança "heróica" a responsável por transformar os Estados Unidos numa grande potência econômica, mas sim os esforços comprometidos de todos os tipos de trabalhadores, técnicos e membros da média administração, além de altos executivos que se importavam profundamente com os produtos, serviços e clientes.

Em 2008, já era difícil encontrar pessoas assim nas companhias abertas, mesmo entre os "recursos humanos" deixados para trás, aguardando sua vez de passar por um "downsizing". E a vez delas chegava em seguida, pois assim que as primeiras demissões criavam problemas para a empresa, logo surgiam clamores para que se fizesse algo ainda mais dramático, ou seja, para que se demitissem mais pessoas, jogando mais lenha na empresa já em chamas.

Macrogerenciamento no chute. Era como se uma nuvem negra tivesse caído sobre o setor empresarial americano, separando as pessoas envolvidas naquilo que as empresas efetivamente faziam - projeto, produção, vendas - daquelas que as controlavam e não estavam tão envolvidas. Estas últimas anunciavam suas grandiosas estratégias e negociavam enormes fusões do alto de suas torres de marfim, seguidas da especificação de padrões de desempenho que todos os outros deviam alcançar. Era o "gerenciamento na base do chute". Interessante notar que o "microgerenciamento" sofria críticas generalizadas enquanto o "macrogerenciamento", conduzido por pessoas em posições de autoridade que não sabiam o que estava acontecendo de fato, destruía as empresas americanas.

Assim, no período que culminou em 2008, tivemos as Enrons, as AOL-Time Warners e as AT\&Ts. Então veio a BP: enquanto gastava fortunas na exibição pública de suas credencias ambientais, a empresa cortava custos com consequências desastrosas no Texas (um incêndio de refinaria que matou 15 pessoas) e no Alasca (um grande vazamento de oleoduto). Na Hewlett Packard, chegou uma nova CEO, anunciando que sua estratégia já estava toda traçada - antes mesmo de passar um só dia na empresa, que dizer, no setor. Assim era o egocentrismo que possuíra a América corporativa. Nunca antes se falara tanto de liderança; nunca antes se viram tão poucas evidências de sua existência.

Essa CEO, como tantos outros, diga-se, percebia-se como uma grande jogadora. E que jogadores eram esses: jogavam com o dinheiro dos outros; ganhavam independentemente de vencerem - com opções de compra de ações; ou de perderem - com seus golden parachutes ("pelos riscos que corremos!", exclamavam). E às vezes ganhavam simplesmente por entrar no jogo, como quando da distribuição de bonificações após a conclusão de uma fusão, antes que sequer se soubessem os resultados. Foi, sim, uma época louca!

\section{Produtividade à custa dos trabalhadores e} gerentes. De volta ao "downsizing", como é que tantas pessoas, em tantas empresas, se tornaram redundantes tão 
subitamente? Será que essas empresas estavam tão inchadas assim? Ou será que seus novos CEOs tiveram insights surpreendentes a respeito de como aumentar a eficiência de uma empresa?

Dado que algumas dessas empresas apresentavam bom desempenho antes do downsizing, a explicação mais provável é a de que esses novos CEOs tenham simplesmente descoberto os benefícios de vender o estoque. Sem dúvida, isso é mais fácil do que aumentar o real valor de uma empresa. Por que se preocupar com atendimento, qualidade e até mesmo - atrevo-me a dizer - sua própria incapacidade gerencial? Tudo isso dá trabalho. Em vez disso, eles mudaram o bottom line para o lado de cima, "chutaram" os lucros e então gerenciaram os custos, em grande parte por meio de demissões.

É claro que nem todos podiam ser demitidos - alguém tinha que ficar para carregar o estoque porta afora. Então a "eficiência" aumentou ainda mais, com os altos executivos despejando seus fracassos nas costas dos trabalhadores e gestores médios remanescentes, que tinham de trabalhar muito mais. Isso, por sua vez, levou a altos índices de "burning out" - que se tornou um termo da moda, na época, e foi significativamente acompanhado da angústia que tantas pessoas sentiam em relação ao setor corporativo dos Estados Unidos. Muito se falou de "hipercompetição", de "ambientes turbulentos", etc., mas isso foi, em grande medida, uma cortina de fumaça para ocultar a confusão mental em que se encontravam os altos administradores. Empresas de administração competente, com estratégias interessantes e trabalhadores dedicados - cada vez menos entre as companhias abertas, diga-se -, simplesmente continuavam a operar.

Essa carga de trabalho a mais poderia ter sido justa se as pessoas tivessem sido remuneradas por seus esforços. Mas não foram. Em sua coluna do New York Times de 5 de dezembro de 2005, Paul Krugman falou do "notável descasamento entre a saúde econômica geral e o destino econômico da maioria das famílias americanas". A renda média real por domicílio "caiu pelo quinto ano seguido", enquanto o número de "americanos sem plano de saúde continua a aumentar", apesar do crescimento "espetacular" dos lucros das empresas desde 2001. Desde os grandes trustes do fim do século XIX não se viam os controladores das grandes empresas americanas arrancar tanto do resto da sociedade. De fato, as taxas de emprego, tais como medidas pelos economistas naquela época, estavam elevadas. Mas de que tipo de emprego estamos falando?

E onde estavam os sindicatos, que a muito custo desenvolveram seu papel de protetores do trabalhador americano? Na altura do ano 2000, haviam sido castrados, graças ao governo Reagan, na década de 1980, e, mais tarde, por conta do colapso do comunismo, que fez com que qualquer esforço coletivo parecesse suspeito e todo tipo de individualismo parecesse grandioso (inclusive, é curioso observar, a "livre empresa" - entidades coletivas disfarçadas de indivíduos, "pessoas" aos olhos da lei: as empresas haviam se tornado pessoas, enquanto as pessoas se tornavam recursos!).

\section{Era preciso servir aos mercados financeiros, e isso significava inaugurar a era da} liderança heróica, para que uma só pessoa pudesse levar implacavelmente todas as outras a elevar o desempenho mensurável de curto prazo, não importava como.

Os fatos atrás das estatísticas. Na coluna citada, Krugman classificou como um "mistério" o "desencanto da maioria dos americanos com a expansão econômica". Fosse ele antropólogo, não economista, mais ligado aos processos internos das culturas corporativas do que às estatísticas que elas geram, talvez não tivesse ficado surpreso.

Não sou antropólogo, mas, naquela época, conversei com muita gente, em diversas partes, de grandes empresas americanas. E ouvia de todos a mesma ladainha. "Henry, você nem imagina o que está acontecendo por aqui”, disse um funcionário de uma grande editora com que eu tra- 
balhava. "Tirei um ano de férias; já não agüentava mais", exclamou um ex-aluno meu que chegara a uma posição graduada no setor de telecomunicações. "Isso aqui é uma piada!", disse um gestor médio de uma empresa de alta tecnologia, "a única coisa com importa para eles é a fusão. Ninguém da alta administração está nem aí para os clientes". Um graduado gerente de vendas que conheci durante um vôo disse que tinha dificuldade para vender máquinas americanas no exterior porque a qualidade e o atendimento haviam decaído.

0 ícone do "Lean and mean". Nenhuma dessas estórias apareceu nas estatísticas dos economistas. Mas qualquer pessoa poderia conhecê-las - qualquer pessoa, por exemplo, que tivesse lido como a Wal-Mart se tornou o ícone empresarial americano da época. Uma honra herdada de empresas como a Dupont e a Ford (em seus primeiros anos), da Hewlett Packard, da IBM e 3M e, mais recentemente, da Intel e da General Electric. Todas eram conhecidas por sua capacidade de inovação; todas haviam sido responsáveis pela criação da potência econômica americana. Então veio a Wal-Mart, famosa por receber os clientes com um sorriso, e também por baixos salários, quebra de sindicatos e economia nos planos de saúde. $\mathrm{O}$

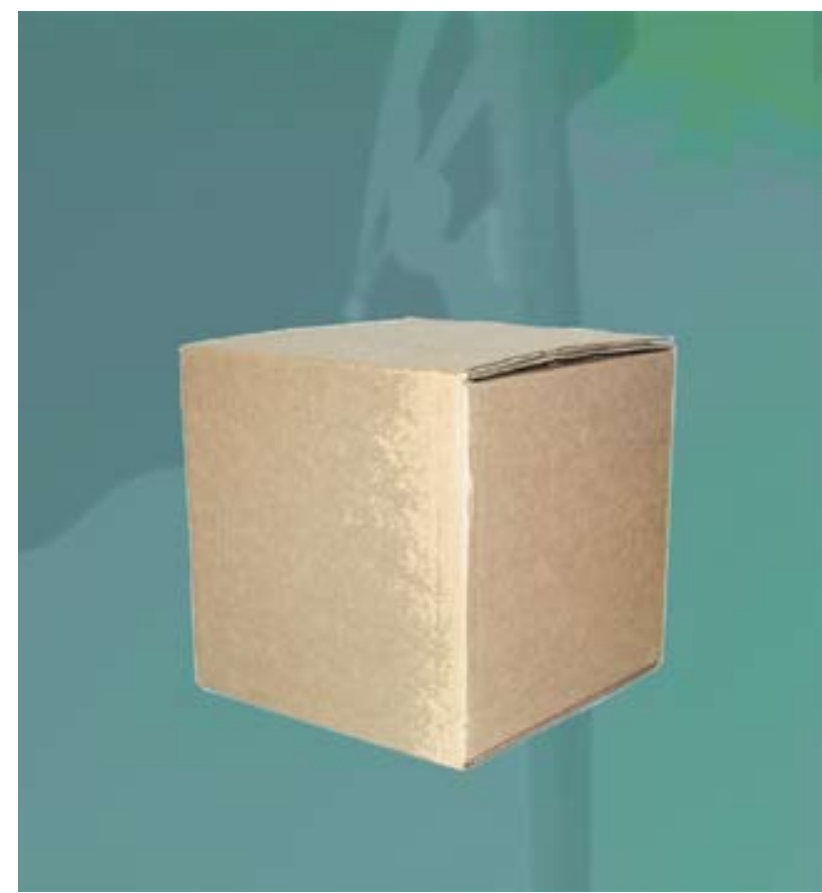

ícone empresaria de então: "Lean and mean" ["enxuta e malvada"] - e como! O que essa frase, tão admirada, nos diz a respeito daqueles tempos?

Do outro lado da moeda, um relatório da OCDE de 2005 observou um "declínio significativo" da intensidade de pesquisa e desenvolvimento nos Estados Unidos. O país construíra sua economia sobre sua capacidade de inovar de desbravar. Os engenheiros americanos eram admirados em todo o mundo. Ao chegar 2008, quando MBAs, financistas e advogados haviam assumido o controle do setor empresarial americano, grande parte dessa inovação se transformara em exploração de outro tipo.

\section{O esforço desesperado para vender "valor ao}

acionista". As corporações são instituições sociais - são comunidades. Funcionam melhor quando seres humanos comprometidos trabalham em relações cooperativas, sob condições de respeito e confiança. Se isso for destruído, a instituição empresarial como um todo entra em colapso.

A menos, é claro, que os concorrentes sejam tão ruins quanto ela. Assim, naqueles dias, os políticos, economistas e empresários americanos embarcaram numa desesperada campanha para promover em todo o mundo sua visão de valor para o acionista. Chamaram a isso de "globalização", mas era apenas um esforço para vender um modelo administrativo que estava fracassando nos Estados Unidos. Pode-se dizer que era exportar tristeza - deixar que os outros compartilhassem do "desencanto" de que falou Krugman.

Algumas empresas de outros países caíram no conto e muitas delas entraram em colapso. Mas também houve muita resistência, especialmente em países com fortes tradições empresariais próprias, como Japão, Alemanha e França (cuja resistência foi especialmente criticada pela mídia americana - podia ser um bom lugar para viver, mas simplesmente não era um país "produtivo").

O Japão, com sua cultura corporativa relativamente igualitária e sua visão de longo prazo, era um caso especialmente interessante. O estilo japonês de gestão era uma febre nos Estados Unidos na década de 1980. Mas isso se esvaiu com a ascensão do valor para o acionista, enquanto surgiam problemas na economia japonesa. "Vejam como nos tornamos eficientes", proclamavam os arautos empresariais americanos, enquanto criticavam o estilo japonês de 
administrar. Mas seria esse o problema do Japão, ou poderia haver outros fatores econômicos envolvidos, inclusive o sistema bancário? A resposta era evidente naquilo que permanecia o ícone do Japão, a mais completa tradução do estilo japonês de gerir: a Toyota, que alçava vôo enquanto a General Motors afundava.

Havia outras possibilidades? Teria sido possível interromper o processo antes do colapso? Com certeza havia medidas que poderiam ter sido tomadas antes de 2008. Por exemplo, fazer com que os analistas financeiros largassem do pé das empresas. Era quase como se elas estivessem sendo administradas a partir dos escritórios daquelas pessoas, que insistiam em mudanças profundas sem ter o menor conhecimento do que realmente acontecia nas corporações, e sem se importar com seu futuro a longo prazo. Mais empresas poderiam ter tirado suas ações das Bolsas, ou simplesmente não as ter colocado nelas. Havia outros meios, mais pacientes e sensatos, de financiar o empreendimento.

As empresas também poderiam ter levado a sério a "governança corporativa". Em vez de simplesmente reorganizar as cadeiras nas salas de seus conselhos de administração, poderiam ter aberto essas salas a quem, por ter mais em jogo, se preocupava mais profundamente com a saúde do negócio: os empregados.

Acima de tudo, poderia ter havido tentativas de manter os mercenários fora da ala executiva. Bastaria um teste simples: qualquer pessoa que exigisse um pacote pesado de remuneração pessoal, inclusive com medidas de proteção, que a diferenciasse de todas as outras, deveria ter sido dispensada por não fazer jus ao termo "liderança". Quantos, dentre os CEOs das companhias abertas em 2008 - quantos daqueles "líderes" - teriam passado nesse teste?

E agora? Mas nada disso aconteceu. Não até 2008, quando a diabólica coalizão entre ganância financeira e dogmatismo econômico aprisionou os Estados Unidos pelo pescoço. Naquela época, os CEOs deveriam ter sido escolhidos e remunerados de maneira diferente para refletir o fato de que o trabalho em equipe e a saúde corporativa a longo prazo eram importantes, sim, e que os seres humanos eram, na verdade, os "maiores ativos" das empresas. Mais importante, naqueles tempos teria sido necessária uma verdadeira liderança empresarial - preocupada, dedicada, modesta -, juntamente com uma verdadeira atenção à corporação enquanto comunidade.

E agora, o que fazer? Para começar, questionar tudo aquilo que atordoou a economia americana: economistas ingênuos e analistas superficiais; o valor para o acionista que erode o valor da empresa e os valores humanos; a "governança" como desculpa para a centralização do status quo; uma "liderança" que se resume à egomania; a empresa vista como um conjunto de "agentes" desconexos, em vez de uma comunidade de membros engajados; e uma obsessão com a mensuração que inevitavelmente coloca a quantidade à frente da qualidade.

Mesmo naqueles estranhos idos de 2008, havia coisas que poderiam ter sido modelos de bom senso empresarial: uma editora de San Francisco vendeu o capital aos seus autores, que conheciam a empresa e se preocupavam com seus verdadeiros valores (Berrett-Koehlerl); empresas cujos fundadores mantiveram um espírito de desempenho sólido (Costco, Ikea, BMW); grandes cooperativas cujos proprietários eram os trabalhadores (Mondragon, na região basca da Espanha); países onde o capitalismo assumia formas diferentes (Japão); até mesmo uma proeminente multinacional, sediada nos Estados Unidos, cujo CEO foi eleito pelo voto secreto de todos os gestores graduados (McKinsey \& Company - teria ela sugerido isso a quaisquer de seus clientes?).

Só quando entendermos que as empresas trabalham como comunidades para chegar à grandeza, e que as sociedades combinam necessidades sociais e econômicas para atingir o equilíbrio, é que começaremos a sair do abismo em que caímos.

\section{Henry Mintzberg}

Professor na Desautels Faculty of Management, McGill University (Canadá)

E-mail: santa@henrymintzberg.com; mintzberg@embanet.com

Artigo originalmente publicado em http://www.mintzberg.org/ pdf/productivity2008.pdf, 2007. (c) Henry Mintzberg 2007. Todos os direitos reservados. Reproduzido com autorização. www.mintzberg.org 